\title{
The determinants of IT creativity at the regional level: an empirical study
}

\author{
Haiwook Choi, Morehead State University,h.choi@moreheadstate.edu \\ Hae-Yeon Choi, Savannah State University, choi@savannahstate.edu \\ Jahmani Yousef, Savannah State University, jahmaniy@savannahstate.edu
}

\begin{abstract}
This paper addresses what determines IT creativity, the fountainhead of IT innovation, at the regional level. We develops the idea that societal and environmental attributes, rather than individual and organizational attributes, profoundly influence IT creativity at the regional level. We identifies the societal and environmental factors- IT infrastructure, education, diversity, and culture- derived from the creativity literature in IS, organization behavior, and economic geography. The relationship between IT creativity and the antecedents is empirically tested using the data collected from college students. The results suggest that societal and environmental attributes significantly influence regional creativity associated with IT products and services. The paper extends the level of analysis of IT creativity study to the regional level. The findings can be used for future IT creativity studies in different regions.
\end{abstract}

Keywords: IT Creativity, IT Innovation, Creative Region, Societal and Environmental Factors

\section{Introduction}

The development of innovative IT products, services, and processes is considered a major driver of regional economic growth in the current competitive business environment. Regional innovation depends critically on its creativity, which is defined as generating novel and useful ideas related to the product (Amabile, 1988). Florida (2002a) defined a creative class as the professionals whose economic function is to create new ideas, new technology, and/or creative content and argued that the concentration of the creative class is a major contributing force to the economic growth of regions. Literature in economic geography has investigated the impact of creativity on regional growth, and their findings support the importance of the concentration of the creative class at the regional level (e.g., Hansen et al., 2005; Mellander and Florida, 2012; Sleuwaegen and Boiardi, 2014).

In the information systems (IS) area, Couger et al. (1993) promoted conceptualizing and developing creative approaches to IT development for regions and countries to gain competitive advantage and economic growth. This paper refers to the creative approaches to the development of IT products and services as IT creativity. Regional economic growth is largely dependent upon making the region an IT creative region, which is the networked IT creativity community (Batabyala and Yoo, 2017; Eversole, 


\section{Issues in Information Systems}

Volume 22, Issue 1, pp. 292-305, 2021

2005). The IT creative region can create an IT creativity-favorable environment that attracts more creative people, spreads and shares IT creativity efficiently and effectively, and increases its constituent's favorable attitude toward IT creativity (Batabyala and Yoo, 2017; Sleuwaegen and Boiardi, 2014). However, almost two decades after Couger et al.'s (1993) study, the IT creativity studies in IS still focus on individuals and small groups levels (Muller and Ulrich, 2013; Seidel et al., 2010).

The IT creativity study at the level of individuals and small groups in IS is not enough to explain the contribution of IT creativity, and its resulting IT innovation, to the regional economic growth, which is largely driven by forming an IT creative region. In order to fill the gap in IS, this study extends the level of analysis to the regional level and societal and environmental factors influencing the formation of the IT creative region. For that purpose, we 1) identify societal and environmental factors based on the studies in IS, organizational behavior, and economic geography areas and 2) empirically examine the relationship between these factors and IT creativity.

In the following sections, we elaborate IT creativity by adopting the creativity definition from organizational behavior literature and propose a theoretical research model and hypotheses describing the relationship between IT creativity and the factors at the level - IT infrastructure, education, diversity, and culture. Thereafter, we examine the antecedents of IT creativity using structural equation modeling (SEM). Lastly, we present the results of the analysis and discuss the findings and the implications for future research.

\section{Literature review}

Most creativity studies have been done by researchers in organizational behavior and psychological areas. In those studies, creativity is typically defined as producing novel and useful ideas by an individual or a small group of individuals working together, and the successful implementation of creative ideas is considered innovation (e.g., Amabile, 1988; Oldham and Cummings, 1996). The creative ideas concern products, services, processes, and managerial practices, as well as competitive strategies (Olszak and Kisielnicki, 2016). IS literature has adopted this definition to study the IS development creative process (e.g., Cooper, 2000; Tiwana and McLean, 2005) and creativity-related phenomena in IS (Seidel et al., 2010). In the same way, in this paper, IT creativity refers to the creation of novel and useful ideas related to IT products, services, and processes.

The most common approach in IT creativity studies has focused on how individual cognitive attributes influence individual and small group creativity. This approach focuses on how individual cognitive abilities, motivation, knowledge, and creative style influence the process of the individuals developing new ideas and problem solutions, which is called the creative process (Seidel et al., 2010; Udawadia, 1990). The use of such person-specific abilities and traits in the creative process has been widely examined in the organizational behavior literature in conjunction with organizational innovation (e.g., Amabile, 1988; Amabile and Pratt, 2016), in which individual creative processes interact with and mutually influence the organizational innovation process. In IS, Tiwana and McLean (2005) viewed the individual expertise and the integration of the expertise at the project level as important factors for IS development project teams' IT creativity, a perspective that individually held expertise influences creativity in the IS development process primarily through the process of expertise integration at the team level. Such an individual 


\section{Issues in Information Systems}

Volume 22, Issue 1, pp. 292-305, 2021

attributes-specific perspective tends to neglect the situational or environmental context of IT creativity (Olszak and Kisielnicki, 2016; Seidel et al., 2010; Udawadia, 1990).

In addition to individual abilities and traits, the use of IT in supporting and improving individual and group creativity processes and outcomes (Seidel et al., 2010; Tiwana and McLean, 2005) has been investigated. These IT creativity studies include the use of creativity support systems, group support systems, and decision support systems in creative idea generation (Klein and Dologite, 2000), creative problem solving (Markus and Elam, 1997; Ray and Romano, 2013), and creative thinking (Jackson, et al., 2012). In this case, IT was viewed as either technique (Seidel et al., 2010), like individual skills to task domain, or environment (Muller and Ulrich, 2013), enhancing and supporting individual and group IT creativity.

Whereas the focus on the individual attributes and use of IT is more concerned with individual creativity, recent IS and organizational behavior studies are beginning to pay more attention to societal and environmental aspects of creativity. In a group and organizational context, creativity involves a high degree of interdependence between the creative individuals and the work environment. The environmental attributes affect the behaviors of individuals and groups during the creative process, which is called creative behavior (Udawadia, 1990) or creative press or environment (Muller and Ulrich, 2013; Seidel et al., 2010). According to the summary of vom Brocke, et al. (2010), the group-level factors include leadership, group composition, group structure, cohesiveness, and resources availability, while the organizational-level factors include organizational climate, organizational culture, leadership style, structure, and systems. Cooper (2000) viewed the group and organizational factors such as group norms, group diversity, organizational culture, reward systems, resources, and management roles as important factors in IS development process. Muller and Ulrich (2013) added the factors such as demography, culture, risk-taking, and learning and training system to the environmental components of IT creativity.

This study focuses on the environmental perspective of IT creativity at the regional level. This level of analysis requires the elaborate selection of the environmental factors that fit the level in conjunction with the factors examined at the group and organizational levels in previous IS literature. This study adopts Florida's (2002a) 3T model from regional economic growth literature. The 3T model describes talent, technology, and tolerance as the key factors in explaining regional creativity, innovation, and growth. Education has been used as a proxy for talent (Florida, 2002b; Hansen et al.; 2005; Kloudová and Chwaszcz, 2012). Education is aligned with the learning and training systems classified as an environmental factor by Muller and Ulrich (2013). Tolerance refers to the openness to diverse demographic people, and diversity is used to measure tolerance (Florida, 200b). The diversity factors have been examined in IS and organizational studies at the group level (e.g., Cooper, 2000). Technology in this paper refers to IT infrastructure, which is the IT foundation in the region. Muller and Ulrich (2013) categorized IT infrastructure as an environmental factor, and this paper adopts their classification. In addition to the three attributes, culture is added as another major antecedent of IT creativity. As described above, culture has been used as an organizational environment to explain group creativity, such as organizational culture and group norms (e.g., Cooper, 2000; Rudowics, 2003). At the macro-level (i.e., regional and national levels) of understanding IT creativity, the manifestation of the impact of the cultural environment is essential (Rudowicz, 2003; Shao et al., 2019).

From the creativity literature in IS, organizational behavior, and economic geography, this study identifies four factors associated with IT creativity at the regional level - IT infrastructure, education, diversity, and 


\section{Issues in Information Systems}

Volume 22, Issue 1, pp. 292-305, 2021

culture. In the next section, the research model and hypotheses describing the relationship between the four factors and IT creativity are presented.

\section{Research model and hypotheses}

In this section, we examine the theoretical domain of the four environmental factors related to IT creativity, and the associated hypotheses are elaborated.

\section{Information technology (IT) infrastructure}

IT infrastructure is defined as the IT platform shared throughout a region, and it includes reliable technology services, software, equipment, facilities, and structures (Broadbent et al., 1999). According to Dewitt (2003) and Pacauskas and Rajala (2017), IT infrastructure affects IT creativity at the regional level through improving the ability to support people in developing creative ideas and conducting creative work, the ability to link with other people, the ability to share knowledge, and the ability to span boundary capability. First, IT infrastructure provides various creativity tools and techniques to assist people through creative processes and provide stimuli to generate new ideas (Pacauskas and Rajala, 2017). For instance, IT infrastructure tools support such creative activities as visualization of ideas, data and process visualization, data analysis, the combination of ideas, and the rearranging of ideas (Olszak and Kisielnicki, 2016). With such use of IT infrastructure, people can enhance their creative ability to perform creative tasks. Shneiderman (2000) argues that creative people often benefit from the use of technology that raises their potential and ability to explore new domains.

Second, IT infrastructure is a region's knowledge base for task domain and acts as the knowledge-sharing platform to facilitate the region's IT creativity (Sleuwaegen and Boiardi, 2014). IT infrastructure can assist creative individuals in exploring, collecting, sharing, and integrating knowledge during the process of generating creative ideas (Dong et al., 2016). In addition, the networks of knowledge exchange among all actors involved in the creation and diffusion of new ideas are of critical importance in respect to workrelated interactions among the people (Pacauskas and Rajala, 2017). IT infrastructure, such as collaboration tools and the Internet, allows people to work together and collaborate interactively. The interactions and knowledge sharing through IT infrastructure enable the conversion of individual creativity into regional creativity (Ryan et al., 2010).

IT infrastructure also supports the boundary-spanning capability of creative activities, which refers to the absorptive capacity and is defined as the integration of external knowledge into the creative process (Cohen and Levinthal, 1990). The absorptive capacity at the regional level increases constituents' awareness of the pool of available expertise in their community, lowers interpretive ambiguities, and breaks people from confinement in their own thought worlds (Tiwana and McLean, 2005). Niosi and Bellon (2002) argued that regional IT creativity shows strong similarities with external technology absorption by the region. IT infrastructure works as a powerful mechanism for knowledge distribution and idea creation and distribution within and across regions through encouraging interactions among people. This leads to the following hypothesis:

H1: IT infrastructure in a region is positively related to the IT creativity of the region. 


\section{Issues in Information Systems}

Volume 22, Issue 1, pp. 292-305, 2021

\section{Education}

In a contemporary knowledge-based economy, IT creativity in a region is considered the product of creative class intelligence in the region. A creative class is a collection of people whose economic function is to create new ideas and new content related to IT (Florida, 2002b). Intelligence refers to the learning ability of a region, i.e., the ability of the region to absorb information and stimulate the development and use of such IT knowledge (Sleuwaegen and Boiardi, 2014). IT creativity can be improved by significant depth and breadth of knowledge concerning potential IT capabilities and the task domains to which the IT is being applied (Cooper, 2000). Such ability affects creativity by influencing the degree of exploration and the feasibility that more creative problem-solving will be examined (Amabile, 1988).

Education contributes to building a region's intelligence through the production of knowledgeable, talented, and creative people (Florida, 2002b; Sleuwaegen and Boiardi, 2014). Educated people tend to have cognitive styles favorable to taking creative perspectives toward new problems; this refers to the ability to use heuristics for the exploration of new cognitive pathways (Amabile, 1988). The creative class theory states that creative and talented people are more creative in performing their work, and that this creativity can be nurtured through education (Florida, 2002b). Rodríguez-Pose and Crescenzi (2008) demonstrate that the proportion of people with tertiary education serve as an important indicator in explaining the creativity of regions. The tertiary education institutions contribute to developing creative students (Fields and Atiku, 2015), and how the presence of tertiary institutions in a region can boost its creativity potential has been underscored in economic geography literature (Sleuwaegen and Boiardi, 2014). This leads to the following hypothesis:

\section{H2: Education in a region is positively related to the IT creativity of the region.}

\section{Diversity}

Diversity encompasses a range of differences within the workforce's demographic background, such as ethnicity/nationality, gender, function, ability, language, religion, lifestyle, or tenure (Kossek and Lobel, 1996), as well as intellectual capability (Bassett-Jones, 2005). Diversity affects a region's ability to facilitate the development and diffusion of human resource combinations, ways of working, and new ideas (Sleuwaegen and Boiardi, 2014). According to Florida (2002b), diversity attracts different types of people with different IT skill sets and ideas. He stated that these diverse mixes of people are more likely to generate new combinations of IT skillsets and ideas and create a concentration of diverse mixes, called diverse concentration. Bassett-Jones (2005) suggested that greater and more diverse concentrations of creative people speed up the flow of knowledge and, in turn, lead to higher rates of IT creativity. Especially, the spatial concentration of diverse people increases personal interactions and contributes to creating dynamic knowledge externalities, generating creative ideas about IT products, services, and processes (Desrochers, 2005).

Because many IT creativity techniques require mental exertions in work-related and non-work-related domains (Couger et al. 1993), diverse experiences inside and outside of the work domains can increase the possible alternative ideas for IT problem-solving (Cooper, 2000). Increased diversity also leads to lower levels of risk aversion (Latimer, 1998), which promotes a more robust evaluation and acceptance of novel 


\section{Issues in Information Systems}

Volume 22, Issue 1, pp. 292-305, 2021

ideas related to IT products, services, and processes. Florida (2002b) suggests that the diverse concentration is the backbone of IT creativity. This leads to the following hypothesis:

H3: Diversity in a region is positively related to the IT creativity of the region.

\section{Culture}

Culture influences a profound effect on IT creative expression. Culture influences not only which IT services would be expressed, but it also determines how those services are expressed (Ludwig, 1992). In addition to individual capacity, a region's IT creativity is also influenced by the cultures that we live and learn in, largely through social norms and values (Cooper, 2000). Regional and national culture is defined with respect to these four social values: individualism versus collectivism, power distance, uncertainty avoidance, and masculinity versus femininity (Hofstede, 2001). Such cultural values foster or restrain people from expressing their unique ideas and the exploration of new ways of doing (Erez and Nouri, 2010). Cultural values provide the normative basis for motivation to creative idea generation, idea selection, and acceptance in a region (Chiu and Kwan, 2010). Cultural values also determine how social and psychological processes are functioning at different stages of the creative process (Chiu and Kwan, 2010).

Cultural values influence which specific characteristics of creative IT ideas are considered when IT creativity is evaluated by communities in different stages of the creative process (Hempel and Sue-Chan, 2010). Erez and Nouri (2010) argued that in regional contexts, cultural values explain the influences on creativity better than individual cognitive differences. This leads to the following hypothesis:

H4: Culture in a region is positively related to the IT creativity of the region.

\section{Methodology and results}

We collected data through a self-administered questionnaire from college students in four cities in Korea the first, second, and fifth-largest cities and a medium-sized regional city. From the 727 administered surveys, we got 562 useable data. Because our research model investigates the relationships between latent constructs, we used structural equation modeling (SEM) with AMOS to test whether our model was supported by the data and evaluate our hypotheses. The data analysis consists of two steps: first, confirmatory factor analysis (CFA) was performed to test the validity and reliability of underlying latent constructs; second, the hypothesized research model was tested.

\section{Analysis and results of the measurement model}

We developed a measurement model for the instrument, consisting of 5 latent constructs and 23 observed variables. To ensure the observed variables in the measurement model form strong unities to latent constructs and demonstrate good measurement properties (i.e., construct validity and reliability), factor and reliability analyses are most frequently used (Straub, 1989). The CFA results shows that the factor loadings for all five latent constructs are statistically significant at 0.001 level and range from 0.37 to 0.81 . The magnitude and significance of the factor loadings suggest that all indicators were moderately or strongly correlated with their latent constructs. Each construct's Cronbach's alpha in the measurement model was 


\section{Issues in Information Systems}

Volume 22, Issue 1, pp. 292-305, 2021

calculated using its factor loadings and standard error values to assess the construct reliability. A general rule for Cronbach's alpha is that above 0.6-0.7 indicates an acceptable level of reliability (Gefen et al., 2000). The reliabilities of the five constructs, as depicted in Table 1, range from 0.64 to 0.90 , which are above the recommended threshold range of 0.6-0.7.

The measures of model fit indicate sufficient congruence between observed and model-implied covariance matrices. Because there is no clear consensus on a single or a set of measures to assess fit, IS literature reports different sets of measures. This paper reports the fit measures used in widely cited SEM studies in IS (i.e., Gefen et al., 2000; Devaraj et al., 2002). They are observed $\left.\right|^{2}$, goodness-of-fit (GFI), adjusted goodness-of-fit (AGFI), comparative-fit-index (CFI), and the root mean square error of approximation (RMSEA). Values greater than 0.90 for CFI and GFI indicate a good fit (Gefen et al., 2000). AGFI values greater than 0.80 and RMSEA less than 0.10 suggest a good fit (Devaraj et al., 2002).

The observed $\left.\right|^{2}$ for the measurement model is $513.33(\mathrm{df}=217, \mathrm{p}=0.000)$. The GFI, AGFI, CFI, and RMSEA are 0.926, 0.906, 0.906, and 0.049 respectively. Adjusting for degrees of freedom, the normed value of $P^{2}$ is 2.37 . Both the normed value of $\left.\right|^{2}$ and fit indices indicate that the measurement model is a good-fitting model. The magnitude and significance of factor loadings, the Cronbach's Alpha measures, and model fit indices all indicated that the measurement model contains valid and reliable constructs, and thus, we retained the proposed measurement model to test the hypotheses proposed.

Table 1. Constructs, Parameters, and Construct Reliability

\begin{tabular}{|l|l|l|}
\hline Constructs & \multicolumn{1}{|c|}{ Parameters } & Reliability \\
\hline IT Infrastructure & $\begin{array}{l}\text { Competitiveness of overall IT infrastructure. } \\
\text { Financial resources to growing human capital in IT. } \\
\text { Good IT support personnel. } \\
\text { State-of-art IT equipment. } \\
\text { Levels of IT services. } \\
\text { People's preparedness with the necessary IT skills. }\end{array}$ & 0.78 \\
\hline Education & $\begin{array}{l}\text { Educated people's adaption to change and new ideas. } \\
\text { Educated people's creativeness in doing things. } \\
\text { Teachableness of human creativity. }\end{array}$ & 0.79
\end{tabular}




\section{Issues in Information Systems}

Volume 22, Issue 1, pp. 292-305, 2021

\begin{tabular}{|c|c|c|}
\hline & Educated people's creative use of skills and knowledge. & \\
\hline Diversity & $\begin{array}{l}\text { Openness to others' attitudes, behaviors, and beliefs. } \\
\text { Openness to others' different ideas. } \\
\text { Openness to various forms of knowledge. } \\
\text { Openness to various lifestyles, including homosexuality. } \\
\text { Openness to international students, workers, investors. } \\
\text { Expression of opinion. } \\
\text { Variety in life. }\end{array}$ & 0.90 \\
\hline Culture & $\begin{array}{l}\text { The propensity to create new IT in collectivistic cultures. } \\
\text { The propensity to create new IT in individualistic cultures. }\end{array}$ & 0.77 \\
\hline IT Creativity & $\begin{array}{l}\text { Creative competition in IT. } \\
\text { Government's investment on IT R\&D. } \\
\text { Private sectors' investment on IT R\&D. } \\
\text { Theoretical foundations produced from universities' R\&D. }\end{array}$ & 0.64 \\
\hline
\end{tabular}

\section{Analysis and results of the hypothesized research model}

The SEM analysis was used to assess the relationships between endogenous and IT creativity constructs in the hypothesized research model (i.e., structural model). The observed $\mathrm{I}^{2}$ for the model is 712.05 ( $\mathrm{df}=224$, $\mathrm{p}=0.000$ ). The GFI, AGFI, CFI, and RMSEA are 0.902, 0.879, 0.868, and 0.062, respectively. Adjusting for degrees of freedom, the normed value of $P^{2}$ is 3.18. Even though the CFI is a bit less than the recommended (0.90), all other fit indices and the normed value of $\left.\right|^{2}$ indicate that the hypothesized research model is a good-fitting model. Figure 1 presents a graphical representation of the model with path coefficient $(\circledR)$ for each construct. All path coefficients are statistically significant at the 0.05 or 0.005 level. The values of path coefficients range from 0.11 to 0.96 . SEM analysis shows that education, diversity, culture, and IT infrastructure are significantly associated with IT creativity at the 0.005 or 0.05 level, and the fit indices are within the desired range and indicate a good fit of the data to the proposed models. Therefore, H1, H2, H3, and H4 were supported.

Cohen (1988) provides recommendations for path coefficient interpretation in social science. Standardized path coefficients with absolute values less than 0.10 indicate a "small" effect; values around 0.30 a "medium" one; and values of 0.50 or more indicate a "large" effect. Based on his recommendation, the structural model as illustrated in Figure 2 shows that education $(\AA=0.96)$, diversity $(\AA=0.30)$, culture $(\AA$ $=0.37)$, and IT infrastructure $(\AA=0.11)$ have an impact on IT creativity with large, medium, medium, and small effect sizes, respectively. 


\section{Issues in Information Systems}

Volume 22, Issue 1, pp. 292-305, 2021

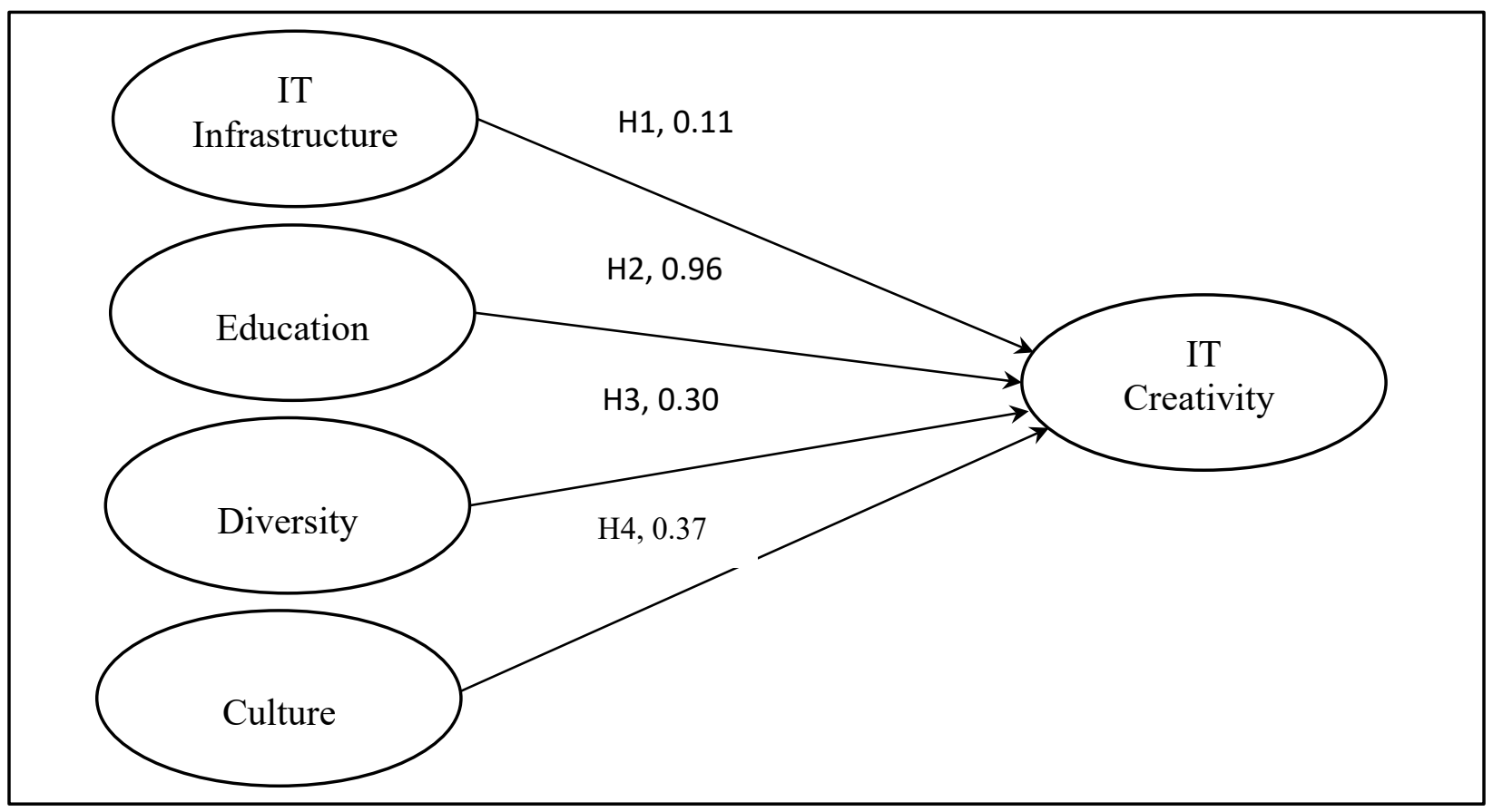

${ }^{a}$ The $L s$ and ${ }^{\mathrm{TM}_{\mathrm{S}}}$ are omitted for schematic simplicity

Figure 1. Hypothesized Research Model and Results ${ }^{\text {a }}$

\section{Discussion and conclusion}

This paper extended the level of analysis of IT creativity study from individual and organizational level to the regional level, and analyzed the impact of the societal and environmental factors on IT creativity. The current study examined the relationships between IT creativity and the antecedents using the data collected from college students.

Table 2. Summary of Hypothesis Tests

\begin{tabular}{|l|l|l|}
\hline Hypothesis & Supported & $\circledR(\mathrm{t}-$ Value $)$ \\
\hline H1: IT Infrastructure Q IT Creativity & Yes & $0.11(2.03)^{* *}$ \\
H2: Education D IT Creativity & Yes & $0.96(6.75)^{* *}$ \\
H3: Diversity D IT Creativity & Yes & $0.30(4.84)^{* *}$ \\
H4: Culture D IT Creativity & Yes & $0.37(3.09)^{*}$ \\
\hline$*$ indicates $p<0.05 ; * *$ indicates $p<0.005$ & \\
\hline
\end{tabular}

The factors we examined were education, diversity, culture, and IT infrastructure. The findings of this study complement previous studies on the topic and revealed interesting information. All the factors are significantly associated with IT creativity, but the magnitudes of their effect range from small to large (See Table 2). The large effect of education indicates that education has a profound influence on IT creativity. This finding supports the results of previous studies in creativity theory in economic geography, indicating 


\section{Issues in Information Systems}

Volume 22, Issue 1, pp. 292-305, 2021

that educated and talented people are the major driver of creativity (Florida, 2002b; Hansen et al.; 2005; Kloudova and Chwaszcz, 2012). This finding also supports IT creativity studies with knowledge and individual cognitive factors in IS research (Muller and Ulrich, 2013).

The significant association of diversity and culture with IT creativity confirms that openness and tolerance to people with diverse demographic and functional backgrounds, and the norms governing the region and nation are the key determinant of IT creativity (Cooper, 2000; Hansen et al.; 2005). The interesting finding is the relatively smaller effect size of the culture-IT creativity association than expected. The discrepancy may originate from the multifaceted characteristics of the culture. Individualistic and collectivistic cultures impact creativity in different ways (Erez and Nouri, 2010). IT creativity might be more affected by modernization than the culture (Khaleefa et al., 1997). When the influence of individualistic and collectivistic cultures is analyzed separately, a better interpretation of the phenomenon would be obtainable. In addition, the research on the two strands of culture with the different measures of creativity- novelty and usefulness (Paletz and Peng, 2008; Shao et al. 2019)- will contribute to a better understanding of culture on IT creativity.

The most interesting finding is the IT infrastructure. It is significantly associated with IT creativity, but this study found that IT infrastructure did not have as large an effect as expected, based on the weight given to it by creativity literature. IT infrastructure seems to be broad because IT infrastructure is an IT foundation of a region and nation. In fact, creativity studies have considered technology, not just information technology only. In IS, a specific type of IT directly supporting idea generation and creativity, such as creativity support systems (CSS) and decision support systems (DSS), are examined on IT creativity (Olszak and Kisielnicki, 2016). In this way, the role of IT on IT creativity can be better explained.

This study has limitations with data collection. The sample subjects are college students, and the research model was assessed based the students' perceptions. Although this fact may not adversely affect this study's findings, there is no question that the results of this study could be enhanced by collecting data from the subjects in IS fields or more diverse populations.

\section{References}

Amabile, T. M. (1988). A Model of Creativity and Innovation in Organizations. In B. Staw and L. L. Cummings (eds.), Research in Organizational Behavior (Vol. 10, pp. 123-167). JAI Press Inc., Greenwich, CT.

Amabile, T. M. and Pratt, M. G. (2016). The Dynamic Componential Model of Creativity and Innovation in Organizations: Making Progress, Making Meaning. Research in Organizational Behavior, 36, 157-183.

Bassett-Jones, N. (2005). The Paradox of Diversity Management, Creativity and Innovation. Creativity and Innovation Management, 14(2), 169-175.

Batabyala, A. A. and Yoo, S. J. (2017, February). On Research and Development in a Model of Schumpeterian Economic Growth in a Creative Region. Technological Forecasting and Social Change, 115, 69-74. 


\section{Issues in Information Systems}

Volume 22, Issue 1, pp. 292-305, 2021

Broadbent, M., Weill, P., and St. Clair, D. (1999). The Implications of Information Technology Infrastructure for Business Process Redesign. MIS Quarterly, 23(2), 159-182.

Chiu, C. and Kwan, L. (2010). Culture and Creativity: A Process Model. Management and Organization Review, 6(3), 447-461.

Cohen, J. (1988). Statistical Power Analysis for the Behavioral Sciences. Academic Press, New York.

Cohen, W.M. and Levinthal, D.A. (1990). Absorptive capacity: A New Perspective on Learning and Innovation. Administrative Science Quarterly, 35 (1), 128-152.

Cooper, R. (2000). Information Technology Development Creativity: A Case Study of Attempted Radical Change. MIS Quarterly, 24(2), 245-276.

Couger, J. D., Higgins, L. F., and Mcintyre, S. C. (1993). (Un)Structured Creativity in Information Systems Organizations. MIS Quarterly, 17(4), 375-397

Desrochers, P. (2001, Summer). Local Diversity, Human Creativity, and Technological Innovation. Growth and Change, 32, 369-394.

Devaraj, S., Fan, M., and Kohli, R. (2002). Antecedents of B2C Channel Satisfaction and Preference: Validating e-Commerce Metrics. Information Systems Research, 13(3), 316-333.

Dewett, T. (2003). Understanding the Relationship between Information Technology and Creativity in Organizations. Creativity Research Journal, 15(2 \& 3), 167-182.

Dong, Y., Bartol, K., Zhang, Z., and Li, C. (2016). Enhancing Employee Creativity via Individual Skill Development and Team Knowledge Sharing: Influences of Dual-Focused Transformational Leadership. Journal of Organizational Behavior, 37(2), 439-458.

Erez, M. and Nouri, R. (2010). Creativity: The Influence of Cultural, Social, and Work Contexts. Management and Organization Review, 6(3), 351-370.

Eversole, R. (2005). Challenging the Creative Class: Innovation, 'Creative Regions' and Community Development. Australasian Journal of Regional Studies, 11(3), 351-360.

Fields, Z. and Atiku, S. O. (2015). Testing and Operationalizing a Model to Measure Creativity at Tertiary Educational Level. International Journal of Educational Sciences, 9(3), 283-296.

Florida, R. (2002a). The Rise of the Creative Class. New York: Basic Books.

Florida, R. (2002b). The Economic Geography of Talent. Annals of the Association of American Geographers, 92(4), 743-755.

Gefen, D., Straub, D., and Boudreau, M. (2000). Structural Equation Modeling and Regression: Guidelines for Research Practice. Communications of AIS, 4(7), 1-76. 


\section{Issues in Information Systems}

Volume 22, Issue 1, pp. 292-305, 2021

Hansen, K. H., Vang, J., and Asheim, B. (2005). The Creative Class and Regional Growth: Towards a Knowledge Based Approach. Papers in Innovation Studies. Circle - Centre for Innovation Research, Lund University. 1-23.

Hempel, P. and Sue-Chan, C. (2010). Culture and the Assessment of Creativity. Management and organization review, 6(3), 415-435.

Hofstede, G. (2001). Culture's Consequences. Thousand Oaks, CA: Sage Publications.

Holbrook, J.A., Clayman, B.P. (2003). Linkage of Clusters to Research Funding. CPROST Report 04-06.

Jackson, L., Witt, E., Games, A., Fitzgerald, H., Eye, A., Zhao, Y. (2012). Information technology use and creativity: Findings from the Children and Technology Project. Computers in Human Behavior, 28(2), 370-376.

Khaleefa, O.H., Erdos, S. G., and Ashra, I.H. (1997). Traditional Education and Creativity in an Afro-Arab Culture: the Case of Sudan. Journal of Creative Behavior, 31(3), 201-211.

Klein, E. and Dologite, G. (2000). The Role of Computer Support Tools and Gender Composition in Innovative Information System Idea Generation by Small Groups. Computers in Human Behavior, 16(2), 111-139.

Kloudová, J. and Chwaszcz, O. (2012). Transformation of 3T Model towards the Comparison of Creative Centres within the European Union. E M Ekon. Manag., 15(4), 56-70.

Kossek, E.E. and Lobel, S.A. (1996). Managing Diversity: Human Resource Strategies for Transforming the Workplace. Blackwell, Cambridge, MA.

Latimer, R.L. (1998). The Case for Diversity in Global Business, and the Impact of Diversity on Team Performance. Competitiveness Review, 8(2), 3-17.

Ludwig, A. M. (1992). Culture and Creativity. American Journal of Psychotherapy, 46(2), 325-498.

Marakas, G., and Elam, J. (1997). Creativity Enhancement in Problem Solving: Through Software or Process? Management Science, 43(8), 1136-1146.

Mellander, C. and Florida, R. (2012). The Rise of Skills: Human Capital, the Creative Class and Regional Development. Handbook of regional science, Springe.

Muller, S. D., \& Ulrich, F. (2013). Creativity and Information Systems in a Hypercompetitive Environment: A Literature Review. Communications of the Association for Information Systems, 32(1), 175-201.

Niosi, J. and Bellon, B. (2002, September). The Absorptive Capacity of Regions. Paper Presented at Colloque Economie Mediterranee Monde Arabe, Sousse. 


\section{Issues in Information Systems}

Volume 22, Issue 1, pp. 292-305, 2021

Oldham, G. R. and Cummings, A. (1996). Employee Creativity: Personal and Contextual Factors at Work. Academy of Management Journal, 39, 607-634.

Olszak. C. M., \& Kisielnicki, J. (2016). Organizational Creativity and IT-Based Support. Informing Science: the International Journal of an Emerging Transdiscipline, 19, 103-123.

Pacauskas, D. and Rajala, R. (2017). Information System Users' Creativity: A Meta-Analysis of the Link between IT Use and Creative Performance. Information Technology \& People, 30(1), 81-116.

Palctz, S., \& Peng, K. (2008). Problem Finding and Contradiction: Examining the relationship between naive dialectical thinking, ethnicity, and creativity. Creativity Research Journal, 21(2): 139-151.

Ray, D. and Romano, N. (2013). Creative Problem Solving in GSS Groups: Do Creative Styles Matter? Group Decision and Negotiation, 22, 1129-1157.

Rodríguez-Pose, A., Crescenzi, R. (2008). Research and Development, Spillovers, Innovation Systems, and the Genesis of Regional Growth in Europe. Regional Studies, 42(1), 51-67.

Rudowicz, B. (2003). Creativity and Culture: A Two Way Interaction. Scandinavian Journal of Educational Research, 47(3), 273-290.

Ryan, S.D., Windsor, J.C., Ibragimova, B. and Prybutok, V.R. (2010). Organizational Practices That Foster Knowledge Sharing: Validation across Distinct National Cultures. Informing Science: the International Journal of an Emerging Transdiscipline, 13, 140-164.

Seidel, S., Müller-Wienbergen, F., and Becker, J. (2010). The Concept of Creativity in the Information Systems Discipline: Past, Present, and Prospects. Communications of the Association for Information Systems, 27(1), 217-242.

Straub, D. W. (1989). Validating Instruments in MIS Research. MIS Quarterly, 13(2), 147-169.

Shao, Y., Zhang, C., Zhou, J., Gu, T., and Yuan, Y. (2019). How Does Culture Shape Creativity? A MiniReview. Frontiers in Psychology, 10, 1-8.

Shneiderman, B. (2000). Creating Creativity: User Interfaces for Supporting Innovation. ACM Transactions on Computer-Human Interaction, 7(1), 114-138.

Sleuwaegen, L. and Boiardi, P. (2014). Creativity and Regional Innovation: Evidence from EU Regions. Research Policy, 43(9), 1508-1522.

Tiwana, A. and McLean, E. (2005). Expertise Integration and Creativity in Information Systems Development. Journal of Information Management Systems, 22(1), 13-43.

Udawadia, F. (1990). Creativity and Innovation in Organizations: Two Models and Managerial Implications. Technological Forecasting and Social Changes, 38, 65-80. 


\section{Issues in Information Systems}

Volume 22, Issue 1, pp. 292-305, 2021

vom Brocke, J., Seidel, S., \& Simon, A. (2010). Bridging the Gap between Enterprise Content Management and Creativity: A Research Framework. Proceedings of the 43rd Hawaii International Conference on System Sciences. IEEE Computer Society, 1-10. 